\title{
Fundamentals of forecasting indicators of economic activity of executive bodies for sustainable development
}

\author{
Zhanna Chupina ${ }^{1,{ }^{,},}$Olga Sokolnikova ${ }^{2,3,4}$, Oksana Yurchenko $^{2,3,4}$,Elena Ryabinina $^{2,3,4}$, and \\ Alena Veselko ${ }^{2,3,4}$ \\ ${ }^{1}$ People's Friendship University of Russia (RUDN University), 6 Miklukho-Maklaya Str., Moscow, \\ 117198, Russian Federatio \\ ${ }^{2}$ Russian Customs Academy, 140015, Moscow area, Lyubertsy, Komsomolsky ave., 4, \\ Russian Federation \\ ${ }^{3}$ Financial University under the Government of Russian Federation, Moscow, 125993, 49 \\ Leningradsky Prospekt, Russian Federation \\ ${ }^{4}$ People's Friendship University of Russia (RUDN University), 6 Miklukho-Maklaya Str., Moscow, \\ 117198, Russian Federation
}

\begin{abstract}
Forecasting plays a significant role in organizing the economic activities of executive authorities using the example of customs authorities, since this is associated with the ongoing policy of optimizing customs payments administered by customs authorities, ensuring the economic security of the state, improving the quality of customs services and compliance with customs legislation. A wide range of forecasting methods allows them to be applied on the basis of assessing the feasibility of applying one method or another to forecast the main economic indicators of the activities of executive authorities. The analysis of the scientific and methodological base made it possible to form and propose a generalized algorithm for forecasting the indicators of the economic activity of executive authorities. Goal is to develop a generalized algorithm for predicting the indicators of the economic activity of executive authorities using the example of customs authorities.
\end{abstract}

\section{Introduction}

Researches in the field of economics of customs business characterize economic activity as one of the main types of activities of executive authorities - customs authorities. At the same time, this activity is defined as belonging to resource support (logistics support; staffing; financial support; information support; organizational and legal support) or to the processes associated with the implementation of the functions of customs authorities

\footnotetext{
* Corresponding author: lemesheva.87@bk.ru
} 
(customs control of foreign economic activity, currency regulation, protection of property rights to objects of intellectual property) [1].

Therefore, the customs authorities were chosen as the directions for improving the indicators of the economic activity of executive authorities [2]. It is possible to highlight the optimization of payments administered by customs authorities, ensuring the economic security of the state, improving the quality of customs services, as well as compliance with customs legislation [3].

The most significant activity of the customs authorities, affecting the economic security of the state, is the administration of federal budget revenues through customs payments from foreign economic activity [4].

So thanks to this area of activity, the formation of the revenue part of the federal budget of the Russian Federation is ensured, which in 2019. amounted to $31.1 \%$ or 4048.05 billion rubles [5], including customs payments from the export of oil, natural gas and petroleum products 1950.3 billion rubles of federal budget revenues. At the same time, the fulfillment of the forecast value for the administration of customs payments is noted at the level of $102.8 \%$ [6].

However, to ensure such a level of replenishment of the federal budget, it is necessary to carry out forecasting, planning and evaluation of the economic indicators of executive authorities - customs authorities on an ongoing basis [7].

Therefore, the task of forecasting is to identify the most likely variant of changes in the results of the activities of executive authorities in the emerging economic situation based on the available information [8].

Considering forecasting in a theoretical aspect, it can be emphasized that this is the process of creating economic forecasts, which is based on scientific methods of cognizing economic phenomena and using the entire set of methods, means and methods of economic forecasting [9].

Since all economic systems are in continuous development, forecasts of various temporal aspects must be developed and agreed upon. So medium-term forecasts are based on promising directions, which are fixed in the long-term forecast, and short-term on the basis of indicators of medium-term forecasts [10].

Forecasts in the customs authorities can be classified according to the following criteria [11] (Fig. 1):

- by the purpose of development;

- by the forecasting period;

- by development methods;

- to provide numerical results;

- according to the criterion of the nature of the development of the object in time.

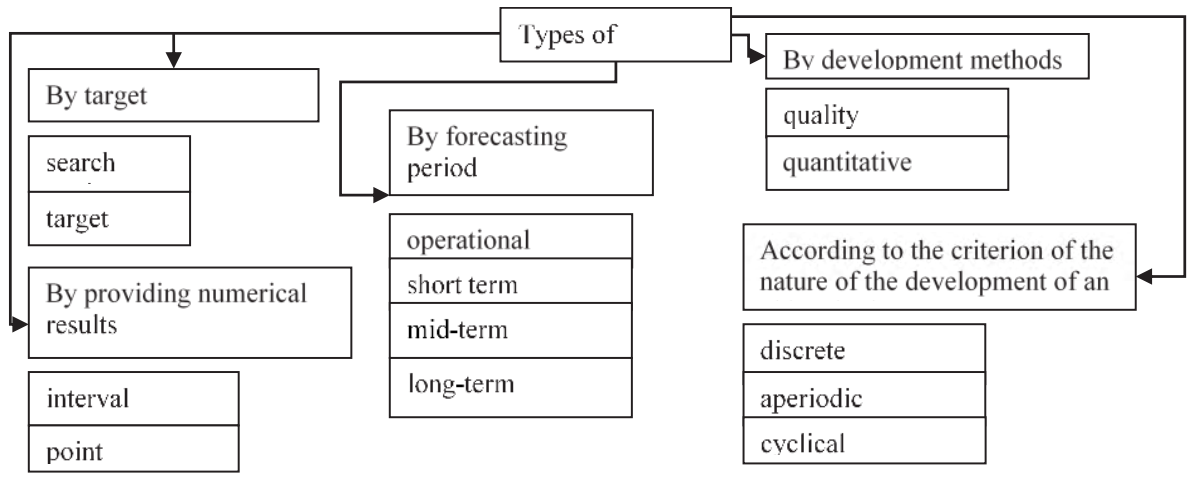

Fig. 1. Classification of forecasts 
Forecasting in executive authorities (customs authorities) is focused on the following directions [12]:

- carrying out scientific analysis of economic, scientific, technical and social processes;

- Foreseeing economic situations during the development of an object and identifying economic problems;

- study of objective relationships between socio-economic processes under certain conditions and at a specific period of development of the object;

- estimation of the forecasting object;

- identification of alternatives for the development of the object;

- accumulation of scientific material for a reasoned choice of optimal solutions.

In the development of the methodology for forecasting economic processes, an important role was played by the scientific developments of domestic and foreign scientists A.G. Aganbegyan, I.V. Bestuzhev-Lada, L. Klein, V. Goldberg. In these works, priority is given to the meaning, essence and functions of forecasting, its purpose in the planning system, as well as problematic aspects of the methodology and organization of forecasting.

In scientific literature, forecasting methods are understood as a set of techniques and methods of thinking that allow, based on the analysis of retrospective data, exogenous (external) and endogenous (internal) connections of the forecasting object, as well as their measurements within the framework of the phenomenon or process under consideration, to derive judgments of a certain certainty regarding the object of the future development [13].

The primary sources of initial information for predicting the main indicators of the economic activity of executive authorities, namely, customs authorities, are statistical data on the dynamics of movement of goods across the state border, data on the values of the indicators under consideration in periods preceding the planned one, as well as information on the capabilities and functioning of executive authorities - customs authorities.

In this regard, the forecasting of the planned values of the indicators of the economic activity of the executive authorities is accompanied by the choice of one of the following conditions [14]:

1. The existence of an objective model that has a causal relationship between the current parameters of the situation model and the expected values of performance indicators.

2. The absence of an objective model, but the presence of a statistical aggregate of the dynamics of the necessary performance indicators in the periods preceding the forecast.

3. Lack of an objective model and reliable initial data required for the use of quantitative methods, but at the same time there are analogues, on the basis of which experts will be able to predict the values of performance indicators.

Each method is applicable to one degree or another to establish the forecast indicators of the customs authorities. Therefore, the task of choosing the most appropriate method for establishing the predicted indicators of customs authorities is non-trivial.

As a basis for solving the problem of choosing a method, it is reasonable to apply a comparative assessment of the forecast capabilities of various methods to establish the planned indicators of the customs authorities. However, the task of choosing a method is complicated by the high degree of uncertainty of the customs authorities. In this regard, it is not possible to carry out a preliminary assessment of the forecasted performance indicators of customs authorities, depending on the chosen method.

Therefore, the assessment and selection of the forecasting method should be carried out directly in the process of establishing the considered planned values of the indicators of the customs authorities. At the same time, based on the conjuncture of the executive authorities, it is reasonable to assess and select an appropriate forecasting method using quantitative methods. However, in the absence of sufficiently adequate models for the functioning of 
executive authorities, the choice of forecasting methods should be carried out using extrapolation methods.

In addition to the above, the choice of an appropriate forecasting method when solving the forecasting problem should ensure the functional completeness, reliability and accuracy of the forecast, namely, satisfy the criteria of truth and verifiability, and also minimize the time and money spent on forecasting [15].

In scientific terms, the methodology for choosing a method and algorithms for predicting the performance indicators of executive authorities was developed in the works of I.D. Akhmadullina, M.S. Polozhentseva, Zh.S. Lemesheva, A.R. Gladkov and others.

So I.D. Akhmadullina in her research has developed a methodological apparatus for predicting one of the indicators of the activities of customs authorities, namely the value of customs payments, which is based on the following methods:

- identification of factors influencing the activities of customs authorities in terms of transferring customs payments to the federal budget;

- the formation of solutions for forecasting customs payments in the tactical management of the activities of customs authorities using regression analysis and an adaptive model [16].

At the same time, the factors influencing the resulting feature are: a set of indicators of the socio-economic development of the state, foreign trade and customs administration. Based on their values, the customs authorities forecast customs payments, while the predicted indicator of the customs authorities is most influenced by GDP and foreign trade turnover in value terms.

The author has developed an algorithm for forecasting customs payments in tactical management of the activities of customs authorities using a regression model, which is based on constructing a forecast according to the initially specified parameters; therefore, the model is not applicable to dynamically changing external and internal conditions. For this I.D. Akhmadullina considers adaptive forecasting models, since they take into account changes in external and internal conditions, and also have high levels of accuracy and reliability.

Thus, the Holt-Withers adaptive model made it possible to increase the forecast accuracy up to $1.7 \%$, while the calculation accuracy of the regression model was $7.3 \%$.

Therefore, the chosen representation of the regression model is not fully justified, since the factors included in the regression model are not directly related to the receipts of customs payments and are not actually used in the preparation of forecasts.

M.S. Polozhentsev, continuing to study the forecasting of the indicator of the executive authorities presented above, develops a forecasting methodology in a non-stationary environment, which includes the following stages of forecasting:

- analysis of the goal, objectives and methodological approaches, as well as the definition of requirements for forecasting the amount of customs revenues under non-stationary environmental conditions;

- development of an algorithm for forecasting the volume of customs revenues under nonstationary environmental conditions;

- development of a model for forecasting the value of customs revenues under nonstationary environmental conditions [17].

The author emphasizes in the work the requirements for the predicted value of customs revenues, such as:

- the forecast should be based on significant indicators and the relationship between them, and should also reflect the mechanism and regularity of the forecasting process;

- determining the balance between the accuracy of the forecast and the complexity of the model used; 
- creation of flexible structures and parameters of the predicted model, changing in accordance with the transformation of the conditions of the environment for the functioning of the customs authorities;

- determining the impact of the customs system on the predicted value of customs revenues.

M.S. Polozhentsev in his work suggests using autoregressive models for forecasting in a non-stationary environment.

However, any socio-economic process is non-stationary in nature, since there is a trend and deviations from it during the period under consideration, therefore the modeling of such processes already implies their non-stationarity. In addition, the presentation of the author's regression model is not fully justified, since the factors included in the regression model are multicollinear with each other, which distorts the model parameters and reduces the forecast accuracy.

In the work of Zh.S. Lemesheva developed a methodological apparatus for planning control indicators of the efficiency of customs authorities, the main provisions of which are:

- principles of planning performance benchmarks of customs authorities and the structure of the scientific and methodological apparatus;

- substantiation of the methodology for determining the planned values of control indicators of the efficiency of customs authorities;

- a methodology for assessing the variability of the planned values of control indicators of the efficiency of customs authorities [18].

At the same time, the author formulates the problem of the achievability of establishing target values of control indicators of the efficiency of customs authorities, since the implementation of this planning principle is due to various factors, which in turn affect the accuracy of establishing target values.

The developed methodology for establishing target indicators of executive authorities is based on the choice of an appropriate method for determining target values and obtaining target values using this model, however, the results obtained will differ from the real ones. In this regard, the author proposes a technique for assessing the variability of planned values, which is based on determining the confidence interval for a given probability of implementing the planned indicator.

However, a generalized presentation of forecasting models is not enough to adequately describe the executive authorities and establish predicted indicators.

In A.R. Gladkov, a scientific and methodological apparatus has been developed to improve the provision of state planning services in customs authorities, including:

- determination of regional conditions of customs administration with the collection of customs payments;

- the methodology for calculating the indicator of the level of collection of customs payments used in planning the activities of executive authorities;

- methodology for expert assessments of indicators used in planning the activities of executive authorities [19].

At the same time, the author distinguishes between the regional conditions of customs administration, which include factors of the macro and microeconomic level. So the factors of the macroeconomic level affect the indicator indirectly, through the establishment of rules for the conduct of foreign trade policy, and the factors of the microeconomic level will include mechanisms for ensuring compliance with customs and tariff regulation measures, the effectiveness of which is determined by the ratio of events of occurrence and detection of violations of regulatory measures at one of the following stages of monitoring fulfillment of obligations by payers.

Forecasting the indicator of executive authorities is considered in four stages, in which the initial forecasting data are the amounts of customs payments calculated on the basis of payers 'information about goods moved across the border, the amount of payments paid on 
the basis of payers' information and taking into account the options for compliance and violation of deadlines by the budget, allocation of various states of occurrence and repayment of payers' debts to the federal budget and the amount of funds returned to the payer, reflecting the results of checking the validity of decisions of customs authorities on calculating payments.

A.R. Gladkova proposes a methodology for expert assessments, which allows taking into account the peculiarities of the economic mechanism for administering customs payments and forming a multi-level system of expert assessments.

\section{Methods}

Forecasting techniques are the basis for forecasting techniques.

Currently, there are over 20 basic forecasting methods, with more than a hundred different modifications of the basic forecasting methods. However, most of them can be attributed rather to separate techniques and procedures that take into account the nuances of the forecast object.

As a rule, the classification of forecasting methods is carried out according to the degree of formalization [20]. In accordance with this principle, two main groups are distinguished (Fig. 1 heuristic (expert, intuitive) methods; formalized (factual) methods.

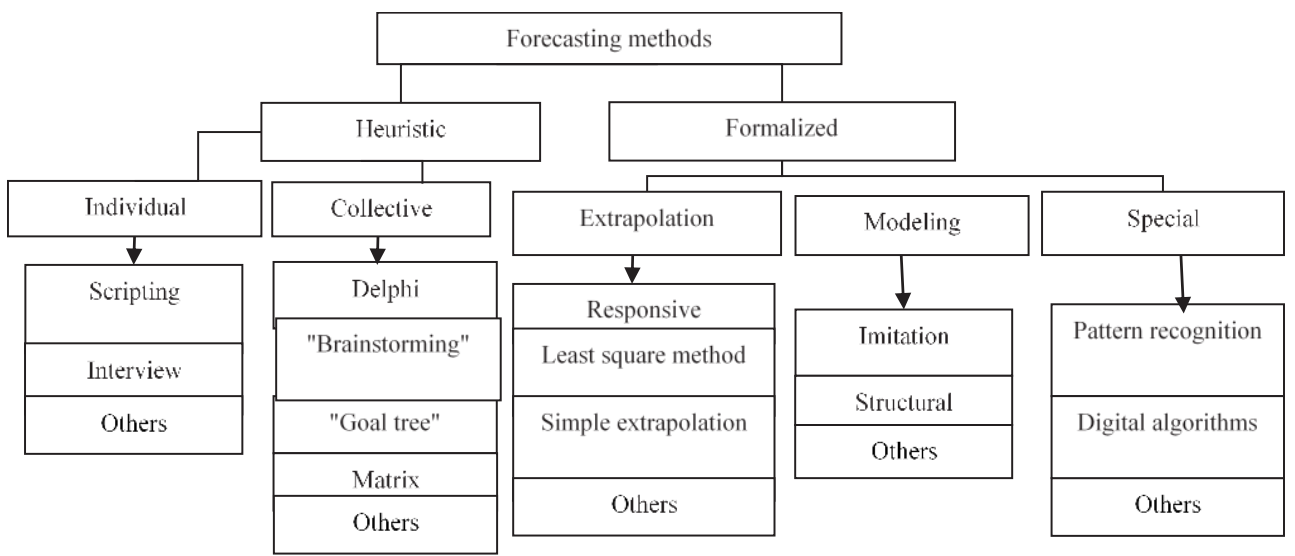

Fig 2. Classification of forecasting methods.

Heuristic methods are used in the study and disclosure of previously unknown, including in the absence of the necessary statistical information and contains the following techniques: individual and collective (the method of introspection, techniques of analogies ("naive" methods), the Delphi method, "brainstorming", morphological analysis and etc.) [21]. Formalized methods are based on logical analysis of facts, statistical data. They are divided into a number of subgroups:

1) According to N.V. Novikova, O. G. Pozdeeva, the methods of extrapolation and modeling should be distinguished.

2) According to G.A. Parsadanova, V.V. Egorova, there are logical and mathematical methods.

3) According to A.V. Romanyuk on forecasting, formalized methods are subdivided [22] into:

- predictive extrapolation methods (simple extrapolation, moving average method, exponential smoothing method); 
- $\quad$ system-structural methods and models (system analysis, regression models, econometric methods, network modeling);

- associative methods (simulation);

- advanced information methods (analysis of publication flows, assessment of the significance of inventions, analysis of patent information).

Therefore, it can be concluded from the analysis of forecasting methods that the presented list of groups and forecasting methods is not complete, since as new forecasting methods appear, the corresponding groups should be replenished. The methods not listed above are either a variation or a concretization of the techniques already presented.

The advantage of formal methods over expert ones lies in the accuracy of the forecast, as well as in the choice of alternative options, while any model, including the mathematical one, is not identical to the object itself. When building such a model, some information about the process is not taken into account, and this can have a negative impact on the accuracy of the forecast.

The main tools used by the Federal Customs Service for forecasting are: modeling, extrapolation and the method of analogues.

The modeling method is a combination of quantitative and qualitative methods, while it differs from all the listed methods in the effectiveness of approaches for predicting indicators, since it is focused primarily on managing the modeled process or phenomenon. The method is based on the establishment of cause-and-effect relationships of the formation of mathematical models and the formation on the basis of modeling of the expected values of indicators of efficiency and effectiveness of executive authorities.

The extrapolation method refers to objective forecasting methods. The essence of the method lies in the fact that previously accumulated data with appropriate characteristics is applied to the predicted event, while the assumption is made that the predicted event will correspond to the available data. This method is relevant in the evolutionary development of the situation, as well as in the presence of an array of initial data necessary for extrapolation. Therefore, the disadvantage of this method is a significant error in the predicted values, in an economically unstable situation.

Methods of analogies make it possible to identify similarities in the patterns of development of various processes of an object or to analyze the dynamics of predicted indicators in previous periods. This category includes the techniques of mathematical and historical analogies, for example, the technique of mathematical analogies is used to predict an object if objects-analogs of another physical nature or other fields of science and technology have a mathematical description of the development process that coincides with the object of forecasting [23]. Moreover, this method is used in the absence of data required for extrapolation or modeling.

\section{Results}

Based on the analysis of scientific literature, an algorithm for predicting the performance of executive authorities can be presented through the main stages occurring at two levels of the customs system (Fig. 2).

Assessment of the information situation. This stage implies the collection and formation of an expert assessment, depending on the information flow coming from each of the contours of management impact on the customs system;

The choice of an appropriate forecasting method based on the information situation, modeling the performance indicator of the customs authorities and calculating the predicted value of the performance indicator of the customs authority with the establishment of a confidence interval; 
Expert assessment of the predicted indicator, in the context of the analysis of trends in the conjuncture of the activities of customs authorities; analyzing the impact of organizational change; analysis of the influence of unaccounted factors; and for the purpose of adjusting the total value of the predicted value with the establishment of a confidence interval;

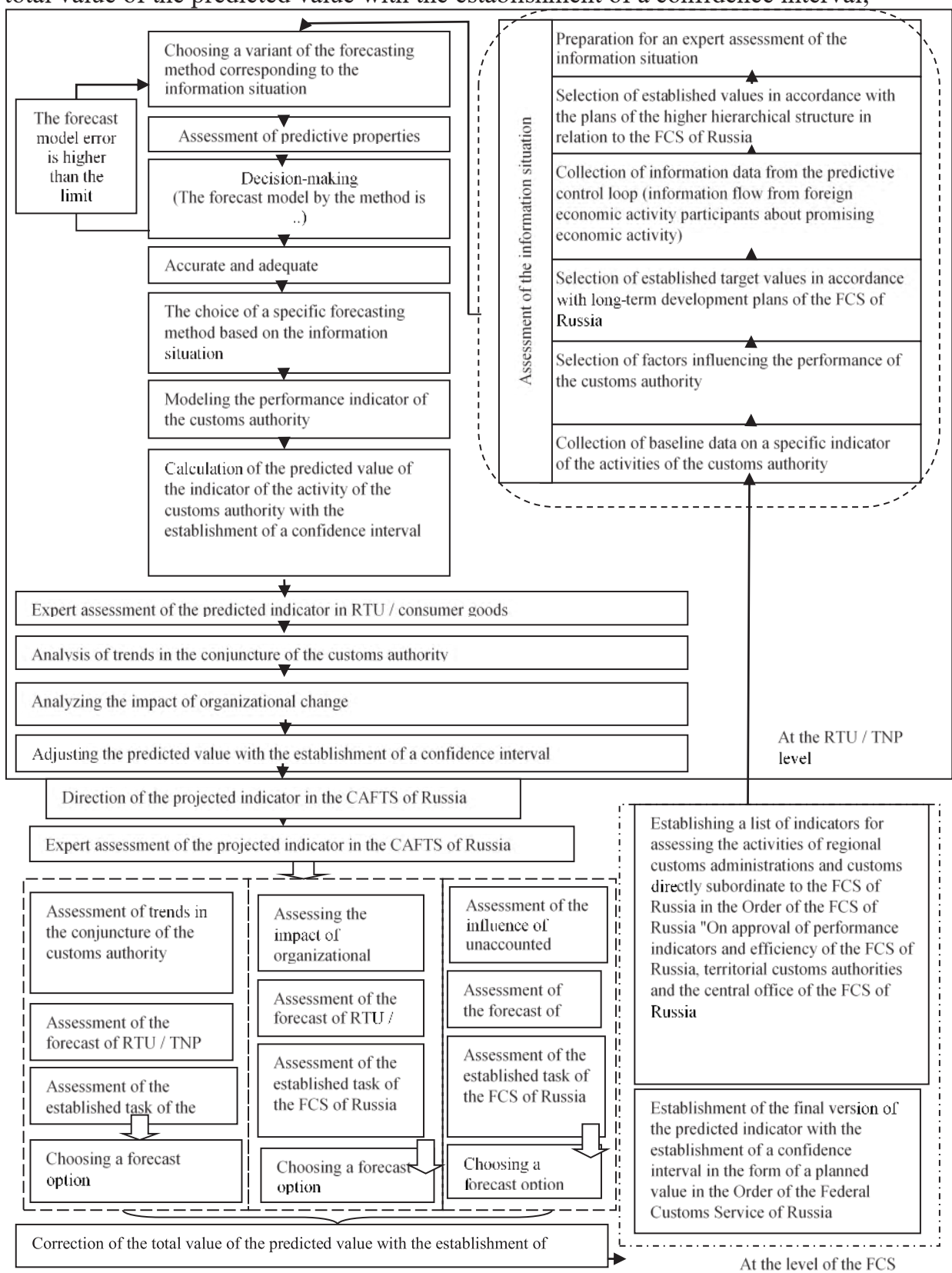

Fig. 2. Technology for forecasting performance indicators of executive authorities (customs authorities). (RTU - regional customs administrations, TNP - customs of direct subordination)

Let's dwell on the formalized forecast model. In the oral understanding of the task of forecasting the effectiveness of indicators of economic activity of executive authorities in the 
region, is as follows. Speaking about a government agency whose interest is in conducting effective economic activity, forecasting indicators is the main goal of the activity. In the course of the process, destructive events occur, which lead to delays and failure to implement decisions. The result of each of these events is an increase in the period until the complete completion of the implementation and update process by an amount $\mathrm{G}$ and an increase in the efficiency of implementation by an amount H. From the standpoint of this formalization model, it is advisable to consider the values of $\mathrm{X}$ and $\mathrm{Y}$ as random variables. The task of this forecast is to determine the probability that the implementation process and the implementation of the process will be completed within the specified time period (directive time T) and the probability that the implementation efficiency will not exceed the specified value $\mathrm{S}$. It will be assumed that $\mathrm{T}$ and $\mathrm{S}$ exceed the required for the implementation of activities ideal timing $T_{0}$, and implementation efficiency $S_{0}$. Thus, according to the conditions of the problem, it is required to determine the probability:

$$
\begin{aligned}
\mathrm{F}_{1}(\alpha)=\mathrm{P}\left(\alpha \leq \mathrm{T}-\mathrm{T}_{0}\right) \\
\mathrm{F}_{2}(\mathrm{~S})=\mathrm{P}\left(\beta \leq \mathrm{S}-\mathrm{S}_{0}\right),
\end{aligned}
$$

Where $\alpha$ - random variable equal to the sum of $\mathrm{n}$ random variables $\mathrm{G}$;

$\beta$ - random variable equal to the sum of $n$ random variables $H$.

Determination of probabilities (1) (2) presupposes knowledge of the distribution functions of random variables $n, G, H$. Usually, public authorities have a huge amount of statistical information. Therefore, only the mathematical expectation $\mu$ the time interval between destructive events leading to an increase in the completion time of the decision implementation process, as well as the mathematical expectations $\hat{\mathrm{G}}, \hat{\mathrm{H}}$ quantities $\mathrm{G}$ и $\mathrm{H}$, production functions caused by these events. In such an information situation, based on the principle of maximum entropy (how much we do not know), the time interval between successive events and the values G, H should be assumed to be distributed over exponential distributions (exponential). The number $\mathrm{n}$ of destructive events is distributed according to Poisson's law:

$$
\mathrm{P}(\mathrm{r}=\mathrm{n})=\frac{\mathrm{v}^{\mathrm{n}}}{\mathrm{n} !} \mathrm{e}^{-\mathrm{v}}
$$

Where $\mathrm{P}(\mathrm{r}=\mathrm{n})$ - probability that the quantity $\mathrm{r}$ destructive events that took place during the implementation of the process of economic efficiency, equal n;

$\mathrm{v}=\frac{1}{\mu}$ - Poisson distribution parameter.

The distribution density function of a random variable $\mathrm{G}$ has the form:

$$
\mathrm{f}_{1}(\mathrm{~g})=\lambda_{1} \mathrm{e}^{-\chi_{1} \mathrm{~g}}, \mathrm{~g} \in\{0,1\}
$$

Where $\lambda_{1}=1 \frac{1}{\hat{G}}$ - parameter of the exponential distribution of the random variable $G$ of the increase in the period of implementation of economic activity due to the onset of the next destructive event.

The distribution density function of a random quantity $H$ has the formf $f_{2}(h)=\chi_{2} e^{-\lambda_{1} h}, h$ $\in\{0,1\}$

Where $\lambda_{2}=1 \frac{1}{\hat{H}}$ - the parameter of the exponential distribution of the random variable $Y$ of the increase in the development efficiency of forecasting the indicators of the economic activity of the executive authorities due to the onset of the next destructive event.

Taking into account relations, (3), (5), the random variables $\alpha$ and $\beta$ are the sums of the Poisson number of exponentially distributed random variables $G$ and $H$. Let us use the apparatus of characteristic functions. 
For a random variable $\alpha$, the characteristic function has the form:

$$
\varphi_{\alpha}(\mathrm{t})=\int_{-\infty}^{\infty} \mathrm{e}^{\mathrm{it} \alpha} \mathrm{dF}_{1}(\alpha)
$$

For a random variable $\beta$ the characteristic function is:

$$
\varphi_{\beta}(\mathrm{t})=\int_{-\infty}^{\infty} \mathrm{e}^{\mathrm{it} \beta} \mathrm{dF}_{2}(\beta)
$$

In relations (6), (7), $\mathrm{t}$ is a real variable, $\mathrm{i}$ is an imaginary unit.

Since the very purpose of using characteristic functions is predetermined by the fact that they have the properties of uniqueness and multiplicativity. The property of multiplicativity is that the characteristic function of the sum of independent random variables is equal to the product of their characteristic functions. The uniqueness property determines that the characteristic function $\varphi_{\mathrm{z}}(\mathrm{t})$ some random variable $\mathrm{Z}$ is absolutely intertwined (integrable) on the entire real axis, and the function $F(z)$ has a continuous derivative $\mathrm{fz}$ (distribution density), then the following relations hold (inversion formula):

$$
\mathrm{f}(\mathrm{z})=\frac{1}{2 \pi} \int_{-\infty}^{\infty} \mathrm{e}^{\mathrm{itz}} \varphi_{\mathrm{z}}(\mathrm{t}) \mathrm{dt} .
$$

Relation (8) indicates a one-to-one correspondence between the characteristic function of the random variable $Z$ and the density function of its distribution.

The characteristic function of the exponential distribution (4) has the form:

$$
\varphi_{1}(\mathrm{t})=\left(1-\mathrm{it} \lambda_{1}^{-1}\right)^{-1}
$$

Taking into account (3), (6), the characteristic function $\varphi_{\alpha}(\mathrm{t})$ distribution (1) is equal to:

$$
\varphi_{\alpha}(\mathrm{t})=\sum_{\mathrm{n}=0}^{\infty} \frac{\mathrm{v}^{\mathrm{n}} \mathrm{e}^{-\mathrm{v}}}{\mathrm{n} !}\left(1-\mathrm{it} \lambda_{1}^{-1}\right)^{-\mathrm{n}}
$$

Using the inversion formula, we find the distribution density function of the random variable $\alpha$ :

$$
f(\alpha)==\frac{1}{2 \pi} \int_{-\infty}^{\infty} e^{i t z} \varphi_{\alpha}(t) d t=\frac{1}{2 \pi} \int_{-\infty}^{\infty} e^{i t z} \sum_{n=0}^{\infty} \frac{v^{n} e^{-v}}{n !}\left(1-i t \lambda_{1}^{-1}\right)^{-n} d t
$$

After changing the order of summation and integration in (11), we get:

$$
f(\alpha)=\frac{1}{2 \pi} \sum_{n=0}^{\infty} \frac{v^{n} e^{-v}}{n !} \int_{-\infty}^{\infty} e^{i t z}\left(1-i t \lambda_{1}^{-1}\right)^{-n} d t
$$

From (12), using the integral from the table of integrals, sums, series and products, the authors I.S. Gradshtein, I.M. Ryzhik, we get:

$$
\mathrm{f}(\alpha)=\sum_{\mathrm{n}=0}^{\infty} \frac{\mathrm{v}^{\mathrm{n}} \mathrm{e}^{-\mathrm{v}}}{\mathrm{n} !} \frac{\left(\lambda_{1} \mathrm{a}\right)^{\mathrm{n}-1} \mathrm{e}^{-\lambda_{1} \mathrm{a}}}{\lambda_{1} \Gamma(\mathrm{n})}
$$

where $\Gamma(\mathrm{n})$ is a gamma function.

From (13) it follows that the probability (1) that the process of forecasting the indicators of the economic activity of executive authorities in the region will be completed within the specified time is:

$$
\mathrm{f}_{1}(\alpha)=\mathrm{P}\left(\alpha \leq \mathrm{T}-\mathrm{T}_{0}\right)=\sum_{\mathrm{n}=0}^{\infty} \frac{\mathrm{v}^{\mathrm{n}} \mathrm{e}^{-\mathrm{v}}}{\mathrm{n} !} \int_{0}^{\mathrm{T}-\mathrm{T}_{0}} \frac{\left(\lambda_{1} \mathrm{a}\right)^{\mathrm{n}-1} \mathrm{e}^{-\lambda_{1} \mathrm{a}}}{\lambda_{1} \Gamma(\mathrm{n})} \mathrm{dt}
$$

The characteristic function of the exponential distribution (5) has the form: 


$$
\varphi_{2}(\mathrm{t})=\left(1-\mathrm{it} \lambda_{2}^{-1}\right)^{-\mathrm{n}}
$$

Using the inversion formula, we find the distribution density function of the random variable $\beta$ :

$$
f(\beta)==\frac{1}{2 \pi} \int_{-\infty}^{\infty} e^{i t \beta} \varphi_{\beta}(t) d t=\frac{1}{2 \pi} \int_{-\infty}^{\infty} e^{i t \beta} \sum_{n=0}^{\infty} \frac{v^{n} e^{-v}}{n !}\left(1-i t \lambda_{2}^{-1}\right)^{-n} d t
$$

Further, after performing transformations similar to (12), (13), we obtain the distribution density function of the random variable $\beta$ as:

$$
\mathrm{f}(\beta)=\sum_{\mathrm{n}=0}^{\infty} \frac{\mathrm{v}^{\mathrm{n}} \mathrm{e}^{-\mathrm{v}}}{\mathrm{n} !} \frac{\left(\lambda_{1} \beta\right)^{\mathrm{n}-1} \mathrm{e}^{-\lambda_{1} \beta}}{\lambda_{1} \Gamma(\mathrm{n})}
$$

It follows from (18) that the probability (2) that the efficiency of forecasting economic activity will not exceed the established value $\mathrm{S}$ is equal to:

$$
f_{2}(\beta)=\mathrm{P}\left(\beta \leq \mathrm{S}-S_{0}\right)=\sum_{n=0}^{\infty} \frac{v^{n} e^{-v}}{n !} \int_{0}^{S}-S_{0} \frac{\left(\lambda_{2} \mathrm{a}\right)^{n-1} e^{-\lambda_{2} \beta}}{\lambda_{2} \Gamma(n)} d \alpha
$$

The main elements of the substantiation of management decisions in the development of a model that provides a forecast of the effectiveness and timing of forecasting indicators of economic activity are the assessment of the results and development of the executive branch in the region. In the early stages of the formation of these solutions, the determination of the cost and time parameters of the renewal and the implementation of the modernization of the process should be based on forecasting. The known methods do not fully take into account the specifics of the processes under consideration, therefore, they can lead to colossal errors in forecasting efficiency. The relations (14) and (18) obtained in this work make it possible to more adequately assess the implementation and forecasting of the indicator of the effectiveness of the economic activity of executive authorities in the region.

\section{Findings}

Direction of the predicted indicator to the CA of the FCS of Russia, for an expert assessment of the predicted indicator, in the context of assessing the trends in the conjuncture of the customs authority; assessing the impact of organizational change; assessing the impact of unaccounted for factors; and for each process in the context of assessing the forecast of the allocated RTU / consumer goods and assessing the established task of the Federal Customs Service of Russia, as well as choosing a suitable forecast option, in order to adjust the total value of the predicted value with the establishment of a confidence interval.

Establishment of the final version of the predicted indicator with the establishment of a confidence interval in the form of a planned value in the Order.

Establishing a list of indicators for assessing the activities of regional customs administrations and customs directly subordinate to the FCS in the Order of the FCS "On performance indicators, performance indicators and indicative indicators of regional customs administrations and customs directly subordinate to the FCS of Russia, for the corresponding year."

Thus, forecasting methods are understood as methods, techniques, with the help of which the development and substantiation of plans and forecasts is ensured, and the modern level of development of the scientific apparatus makes it possible to distinguish a variety of methods for predicting the indicators of executive authorities, classifying them into formalized and heuristic methods. 
Scientific works emphasize that formalized methods are limited in the ability to predict the indicators of executive bodies, while the relevance of expert methods for expanding forecasting capabilities is not listed.

Therefore, the presented technology for predicting the performance indicators of executive authorities takes into account all the main forecasting methods, namely, methods of analogies, extrapolation and modeling, based on the analysis of the information situation and from the appropriateness of application at the stages of forecasting. This algorithm is carried out at all levels of the hierarchical system of executive authorities and includes six stages. In this regard, the rationalization of the forecasting process can help to increase the efficiency and effectiveness of executive bodies.

This paper has been supported by the RUDN University Strategic Academic Leadership Program.

\section{References}

1. Anisimov V.G., Anisimov E.G., Pak A.Yu., Saurenko T.N., Chupina Zh.S., Chupin A.L. Methodological provisions for digitalization of control activities of customs authorities. AllRussian scientific and analytical journal "Financial Economics", No. 4, 2020, p. 6-11, ISSN 2075-7786.

2. Planning in the customs authorities: textbook / E.A. Terekhova, V.N. Shapovalova, Zh.S. Lemesheva, M.O. Gorchak, I. V. Sharoshchenko, V.B. Korovin. M .: Publishing house of the Russian Customs Academy, 2016.193 p.

3. Methods of economic forecasting: textbook / M.M. Butakov. M .: RUSAYNS, 2016.212 p.

4. P. Kivimaa, H.L. Kangas, D. Lazarevic. Client-oriented evaluation of 'creative destruction'in policy mixes: finnish policies on building energy efficiency transition. Energy Res. Soc. Sci., 33 (2017), pp. 115-127, 10.1016/j.erss.2017.09.002

5. Geyer R, Rahani S. Complexity and Public Policy. Complexity and Public Policy; 2014.

6. Zhanna Lemesheva, Oksana Yurchenko, Myron Karpovich, Zinaida Petrikova, Natalya Bratishko, Larisa Garipova. Formation of an effective management structure for enterprises in the energy sector of the economy // E3S Web of Conferences 110, 0 (2019) https://doi.org/10.1051/e3sconf /201911002129;

7. Morkovkin D., Lopatkin D., Sadriddinov M., Shushunova T., Gibadullin A., Golikova O. Assessment of innovation activity in the countries of the world // E3S Web of Conferences. 2020. 157, 04015.

8. Alexey Ukhanov, Alexander Chupin, Zhanna Chupina. Model of economic growth of the economy of small and medium-sized enterprises in the context of the spread of coronavirus infection // E3S Web of Conferences 217, 07016 (2020) https://doi.org/10.1051/e3sconf/202021707016.

9. Morkovkin D.E., Gibadullin A.A., Kolosova E.V., Semkina N.S., Fasehzoda I.S. Modern transformation of the production base in the conditions of Industry 4.0: problems and prospects // Journal of Physics: Conference Series. 2020. 1515, 032014.

10. Borovkova Viktoriya and Borovkova Valeriya 2018 Economic analysis: theory and practice $17 \mathrm{p} .1428-1448$

11. Greenhalgh T, Robert G, Macfarlane F, Bate P, Kyriakidou O. Diffusion of innovations in service organizations: systematic review and recommendations. Milbank Q. 2014;82(4):581-629. doi:10.1111/j.0887-378X.2004.00325.X 
12. K. Araújo. The emerging field of energy transitions: progress, challenges, and opportunities. Energy Res. Soc. Sci., 1 (2014), pp. 112-121, 10.1016/j.erss.2014.03.002

13. Morkovkin D.E., Gibadullin A.A., Safarov B.G., Alpatova E.A. Definition of factors limiting the growth of industrial production // IOP Conference Series: Materials Science and Engineering. 2020. 862 (4), 042013.

14. Zhanna Lemesheva, Ludmila Lavrova, Nikolay Chernegov, Maria Ivanova, Elena Akimova. Development of the mechanism of motivation and tangible incentivisation // January 2018 MATEC Web of conferences 170(2):01094 doi:10.1051/matecconf/201817001094;

15. Klijn EH, Koppenjan JFM. Complexity in governance network theory. Complexity, Governance \& Networks. 2014;1(1):61-70. doi:10.7564/14-CGN8

16. M.P. Hekkert, S.O. NegroFunctions of innovation systems as a framework to understand sustainable technological change: empirical evidence for earlier claims. Technol. Forecast. Soc. Change, 76 (4) (2009), pp. 584-594, 10.1080/09537325.2016.1220515

17. Max Weber. Economy and Society: An Outline of Interpretive Sociology. G. Roth, C. Wittich (Eds.), University of California Press, Berkeley (1922) 1978

18. Mikhaylov A., Moiseev N., Aleshin K., Burkhardt T. Global climate change and greenhouse effect // Entrepreneurship and Sustainability Issues, 2020, 7(4), 2897-2913.

19. Alexander L. Chupin, Oxana A. Yurchenko, Zhanna S. Lemesheva, Anna Y. Pak, Mikhai B. Khudzhatov. Development of Logistical Technologies in Management of Intellectual Transport Systems in the Russian Federation // Part of the Lecture Notes in Networks and Systems book series (LNNS, volume 87). Digital Economy: Complexity and Variety vs. Rationality pp 778-784;

20. Edelenbos J, van Meerkerk I, van Leeuwen C. Vitality of complex water governance systems: Condition and evolution. Journal of Environmental Policy \& Planning. 2015;17(2):237-261. doi:10.1080/1523908X.2014.936584

21. Gibadullin A.A., Romanova J.A., Morkovkin D.E., Pirakov R.M. Assessment of the level of environmental innovation in industrial production and information and communication sphere // Journal of Physics: Conference Series, 2020, 1679(5), 052076.

22. Aganbegyan A.G. Resumption of socio-economic growth: problems and prospects // Srednerusskiy Vestnik of Social Sciences. 2017.Vol. 12.No. 3.P. 19-41. 